\title{
Evaluation of Geotechnical Properties of Sub-Grade Material Used in Road Construction
}

\author{
Bereket Admasu Yimam Mohammed \\ Civil Engineering Department, Wolaita Sodo University, Wolaita Sodo, Ethiopia
}

\begin{abstract}
The aim of this research is evaluation of geotechnical properties of sub grade material used in Bukur-Setera road construction. Tests conducted in laboratory for gravel material are grain size analysis, atterberg limit, free swell, maximum dry density and optimum moisture content. The material strength test was conducted interms of California bearing ratio. Because of less finer materials, the percentage of swelling is low. Gravel materials involved in this investigation have taken a larger CBR value of $21 \%$ for $5 \mathrm{~mm}$ penetration. According to ERA 2013 manual, the materials having good to excellent subgrade materials, having CBR value greater than or equal to $30 \%$. But the actual values are less than $30 \%$. Accordingly, it has a limitation of using the material as sub grade materials.
\end{abstract}

Keywords: Laboratory test, Sub grade, California Bearing Ratio

DOI: $10.7176 / \mathrm{CER} / 11-1-04$

\section{INTRODUCTION}

In this paper, the gravel materials have been collected from the site near to the project. The project area is found in $13 \mathrm{~km}$ to west of Hossana town, south nation's nationalities and peoples region, Ethiopia. Having this, tested natural gravel materials were collected from Laignaw gana deposit area and used for construction of $22.97 \mathrm{~km}$ from Bukur - Setera. Roads and highways are in the center of economic activities in countries where land based communication is dominant. The construction, operation and maintenance of the roadways play vital role in the economy. To get uninterrupted and sustainable service from the roadways, the first requirement is to construct the roads in such a way that these are able to withstand heavy traffic loads and weathering effects during the expected service life [Sheikh S, Nusaeir H., Abdul J. and Mohammad S., 2016].

The soil sub-grade is a layer of natural soil prepared to receive the layers of pavement materials placed over it. The loads on the pavement are ultimately received by the soil sub-grade for dispersion to the earth mass. It is essential that at no time the soil sub-grade is over stressed. It means that the pressure transmitted on the top of sub-grade is within allowable limit, not to cause excessive stress condition to deform the same beyond the elastic limit. Therefore it is desirable that at least top $50 \mathrm{~cm}$ layer of sub-grade soil is well compacted under controlled conditions of optimum moisture content and maximum dry density. It is necessary to evaluate the strength properties of the soil sub-grade [Deepika.Chukka, Chakravarthi.V.K, 2012]. The sub-grade is designed such that the stress transferred should not exceed elastic limit. Hence, the suitability and stability of sub-grade material is evaluated before construction of pavement. Soaked California bearing ratio (CBR) value (\%) is considered as strength parameter in design of sub-grade [ASTM, 2004].

California Bearing Ratio (CBR) is a strength index test that is very commonly applied in thickness design of pavement layers. Where the soaked behavior of the sample is desired, the sample is soaked for 4 days. Both soaked and un soaked CBR tests are used in the assessment of granular materials used in base, sub-base and subgrade [ Osouli, A., Salam, S., Othmanawny, G., Tutumluer, E., Beshears, S., Shoup, H., \& Eck, M., 2017].

\section{MATERIALS AND METHODS}

The soil samples were collected from the site are disturbed and tested in the laboratory. In the preparation of soil samples ready for laboratory tests were ready for tests of grain size, liquid limit, free swell, compaction and California bearing ratio. The studies were involved in the laboratory on dry density and moisture content determination. The coarse grained materials used under this investigation were collected from the specific area having natural gravel soils. The sub grade material classification was conducted according to ASTM and AASHTO standards. 


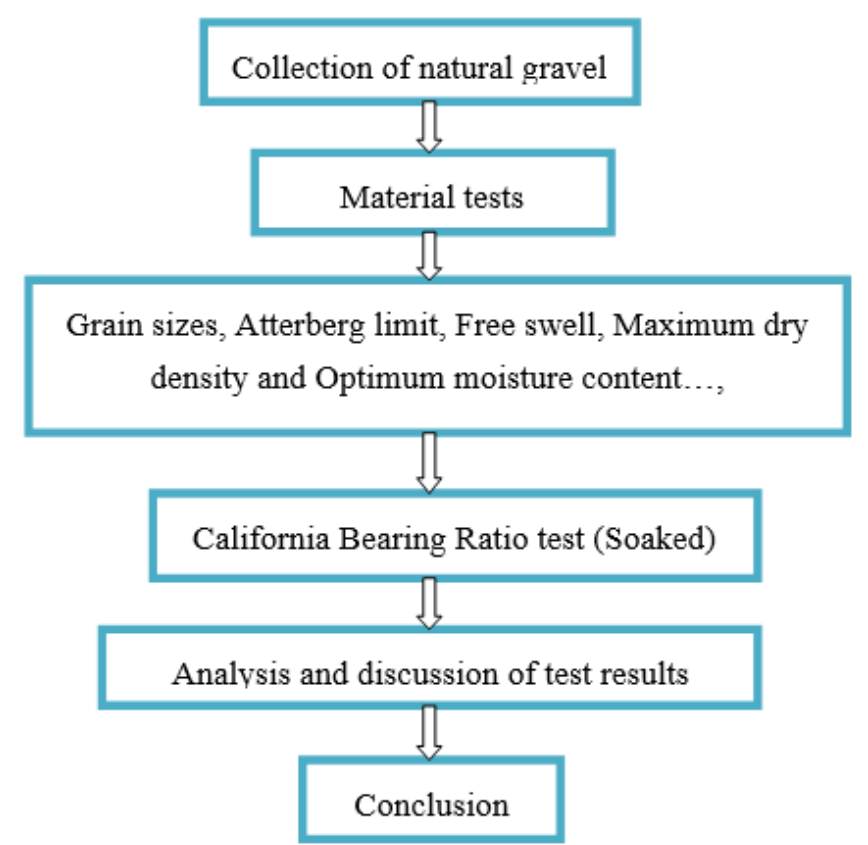

Chart 2.1: Methodology chart

\section{RESULTS AND DISCUSSION}

Some of the geotechnical properties of sub grade materials were prepared for laboratory test. Specifically, the maximum dry density and optimum moisture content are basic engineering properties of soils used for conducting CBR value. Therefore, California bearing ratio values simply show the strength characteristics of these sub grade materials. Table 3.1 presented below show the results obtained for sub grade material from laboratory tests.

Table 3.1: The geotechnical properties of sub grade materials.

\begin{tabular}{|c|c|}
\hline Sub grade material properties & Values \\
\hline \multirow{5}{*}{ Grain size } & 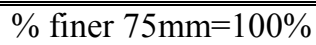 \\
\hline & \%Finer $4.75 \mathrm{~mm}=42.3$ \\
\hline & $\%$ finer $2 \mathrm{~mm}=24$ \\
\hline & \% finer $0.425 \mathrm{~mm}=5$ \\
\hline & \%finer $0.075 \mathrm{~mm}=0.3$ \\
\hline Liquid limit, \% & 30.1 \\
\hline Plastic limit, \% & 27.6 \\
\hline Plastic Index, $\%$ & 2.5 \\
\hline Free Swell, (\%) & 13 \\
\hline OMC, $\%$ & 11.7 \\
\hline MDD, $g \mathrm{gm} / \mathrm{cm}^{3}$ & 2.16 \\
\hline CBR (\%),2.5mm penetration & 17.02 \\
\hline CBR (\%), 5mm penetration & 20.8 \\
\hline AASHTO Classification & A-1-a \\
\hline USCS Classification & GP \\
\hline
\end{tabular}

\section{i. Grain size analysis}

Grain size analysis is used for road materials to determine the involvement of types of particles with definite sizes. Here, the sub grade materials prepared for gradation analysis are generated. These tests are done according to ASTM D422-63 [ASTM D1557, 2002]. The test result is presented in Fig.3.1 below. 


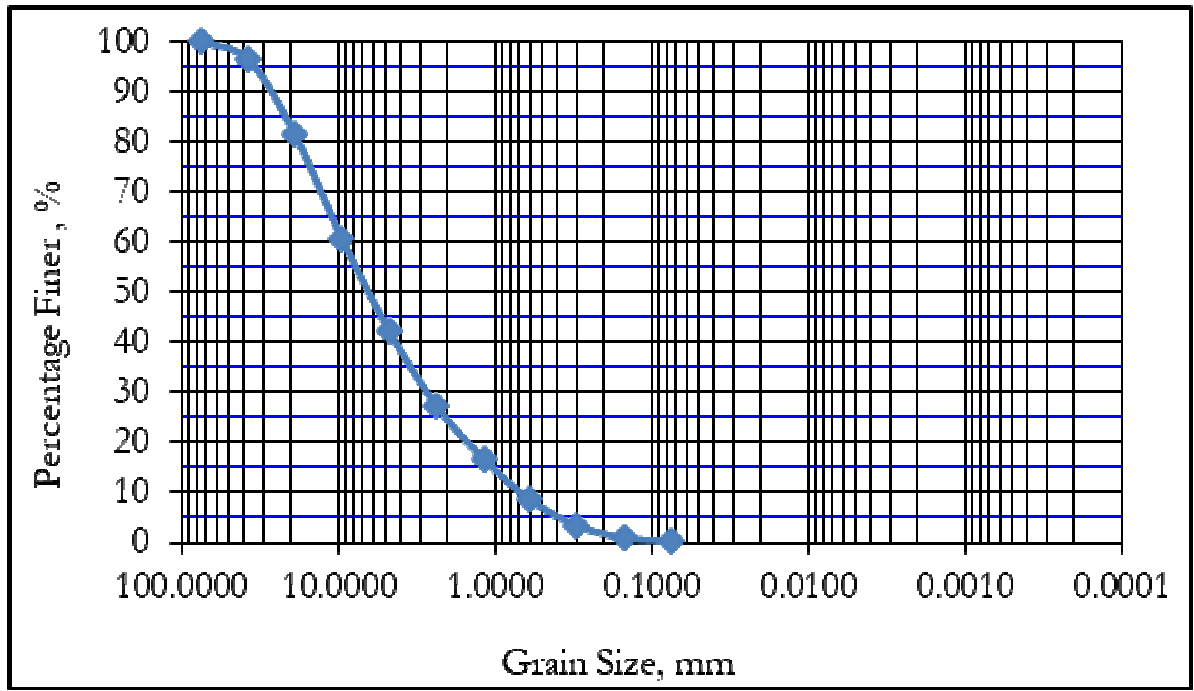

Fig.3.1: Grain size distribution curve

\section{ii. Plasticity Characteristics}

Considering that plastic limits of construction materials must not be in excess of $33 \%$, the soil samples are considered to be within the regulatory standards [G.P. Ojo, U.G. Igbokwe, K.K. Nwozor and C.J. Egbuachor, 2016]. Atterberg limits were determined for air-dried soil samples based on ASTM D 4318-98 -Standard Test Method [ASTM D1557, 2002]. The results are listed in Table 3.1 above. The value of plastic limit of sub grade material is $27.6 \%$.

iii. Swelling characteristics

Actually, the free swell values obtained from laboratory test is $13 \%$. This value shows that, the swelling nature of the material is non expansive. It is true that, the finer material which passes No.200 sieve is only $0.3 \%$.

iv. Compaction Test

The compaction characteristics of gravel soils were determined using modified proctor test (ASTM D1557) [ASTM, 2004] in the laboratory by adding the gravel materials in to 5 layers, each is subjected by 25 number of blows, and with a diameter of mold $=15.35 \mathrm{~cm}$, area of mold $=185.06^{\mathrm{cm}^{2}}$, height of mold=11.6cm, volume of mold $=2146.7^{\mathrm{cm}^{3}}$ and mass of mold of 5070gm. The result obtained from the laboratory is presented in Fig. 3.2 below.

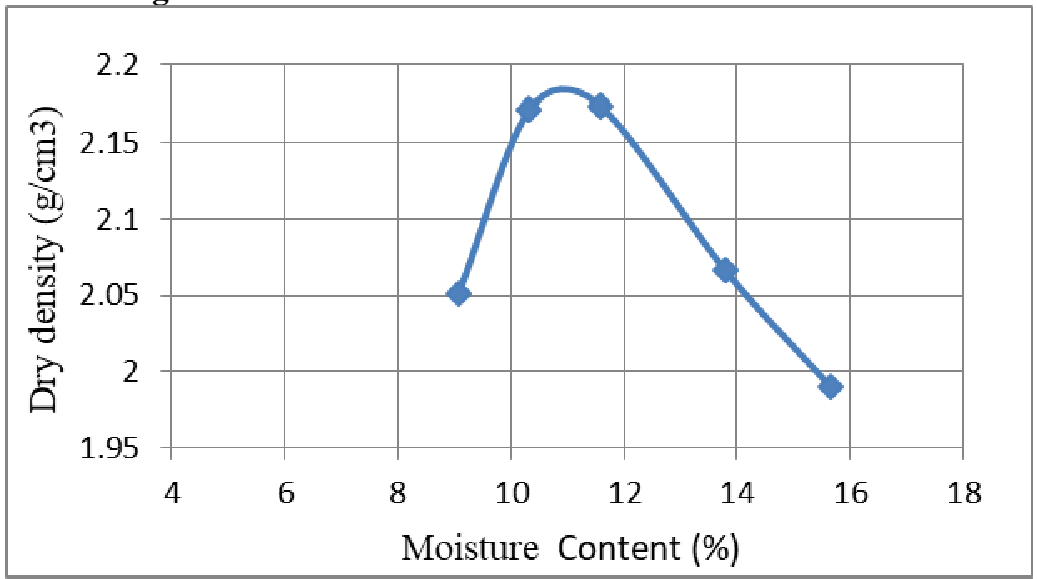

Fig.3.2: Dry density vs Moisture content in laboratory test for determination of MDD

The values laboratory maximum dry density and optimum moisture contents are incorporated in Table 3.1 above.

\section{v. California Bearing Ratio Test}

The test specimens were compacted in accordance with the procedures given in ASTM-D 1557[ASTM, 2004] using modified effort. The soil at the optimum water content (OMC) was placed in 5 layers within CBR mould. The soil samples are compacted in CBR mould at its optimum water content and then the CBR tests were carried out under soaked conditions [Charles A. Adams, Ernest Apraku, Richter Opoku-Boahen , 2015].

To perform the CBR tests, we performed Proctor tests in order to compact the ten soils under their optimum 
unit weight. The material is compacted at its optimum moisture content. The molds are soaked for four days, and, then, mold is tested under CBR with different ring loadings. The first with no ring loading, the second with one ring loading, thirdly, with two rings loading. Fourthly, with three rings loading and finally, with four rings loadings. The results of this CBR test on the soil under different surcharge rings are collected in a chart showing the pressure applied to the soil in KiloPascal versus the penetration of the piston in millimeter. According to the ASTM standards, the CBR test should be performed under two loading rings having weight of $44.5 \mathrm{~N}$. In order to study the effect of the surcharge applied on the soil on its CBR value, the below figures are prepared [Robert Nini, 2018]. And also Ethiopian Road Authority (ERA) [ERA, 2013], material CBR test involved in road construction takes place four-day-soaking. By keeping in mind this, the CBR values evaluated for $2.5 \mathrm{~mm}$ and $5 \mathrm{~mm}$ penetration are $17.02 \%$ and $20.8 \%$ respectively. The CBR value obtained from the test is presented in Fig.3.3.

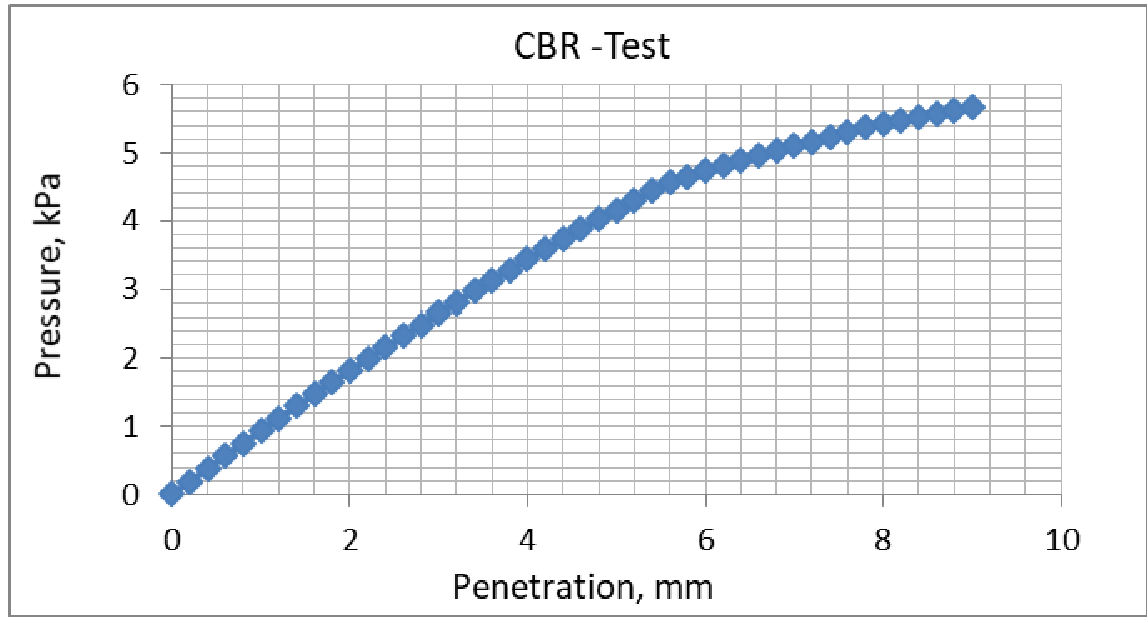

Fig. 3.3: Pressure versus penetration of Bukur-Setera sub grade sample under continuous load with different rings Loadings.

The amount of gravel material retained on sieve $4.75 \mathrm{~mm}$ is greater than $57.7 \%$. The sand material passing sieve size $4.75 \mathrm{~mm}$ and retained on $0.075 \mathrm{~mm}$ is $42 \%$. According to Unified Soil Classification System [ASTM, 2004], the selected material used as sub-grade materials are dominated by gravel soils (GP). Based on AASHTO classification system [AASHTO, 2004], the gravels found in the category of A-1-a with zero group index. Actually, the result obtained from CBR test shows that the dry density is increased after soaking. The plastic limit is less than $33 \%$ and found within the regulatory standards presented in [G.P. Ojo, U.G. Igbokwe, K.K. Nwozor and C.J. Egbuachor, 2016].

The lower OMC causes for the value of CBR to be higher. Additionally, the percentage of finer are lower the CBR value increases. Here, the CBR values in involving 10-20 are be able to used as sub-grade for high ways, express ways and as top surface materials for road type may expose to weathering or erosion.

\section{CONCLUSION}

The geotechnical properties of sub grade materials are evaluated and have a value of plastic index, free swell, maximum dry density (MDD) and Optimum Moisture Content of $2.5 \%, 13 \%$, and $2.169 \mathrm{~m}^{2} \mathrm{~cm}^{2}$ and $11.7 \%$ respectively. Percentage finer passing sieve size $0.075 \mathrm{~mm}$ is very lower, less than $0.3 \%$. It is purely coarse grained soil. Under the classification of tested soils, it belongs to categorized in A-1-a (AASHTO) and GW (USCS). The higher the percentage of gravel gives higher MDD and lower OMC values. Even though, the plastic index value obtained from the laboratory analysis is less than $5 \%$ and the CBR value leads to be increased; the actual soaked sample CBR value are $17.02 \%$ and $20.8 \%$ for $2.5 \mathrm{~mm}$ and $5 \mathrm{~mm}$ penetration respectively. Therefore, according to the sample group index-zero value and the larger CBR value is used as sub grade material in road construction.

\section{ACKNOWLEDGMENT}

The authors appreciates and thanks the financial support (cover) of ETAB construction association for the tests were performed in the laboratory

\section{REFERENCE}

AASHTO, (2004). Standard specifications for Transportation materials and Methods of Sampling and Testing. U.S America.

ASTM, (2004). Special Procedures for Testing Soil and Rock for Civil Engineering Purpose. U.S America.

ASTM D1557, (2002), "Standard test methods for laboratory compaction characteristics of soil using modified 
effort," American Society for Testing and Materials, West Conshohocken, PA.

Charles A. Adams,*, Ernest Apraku, Richter Opoku-Boahen (2015), Effect of Triaxial Geogrid Reinforcement on CBR Strength of Natural Gravel Soil for Road Pavements, Takoradi, Ghana.

Deepika.Chukka, Chakravarthi.V.K (2012), Evaluation of Properties of Soil Sub grade Using Dynamic Cone Penetration Index - A Case Study, Andhra Pradesh, India

Ethiopian Road Authority (ERA) (2013), Pavement design manual volume I flexible pavements, Ethiopia.

G.P. Ojo, U.G. Igbokwe, K.K. Nwozor and C.J. Egbuachor (2016), Geotechnical Properties of Lateritic Overburden Materials on the Charnockite and Gneiss Complexes in Ipele-Owo Area, Southwestern Nigeria, Nigeria.

Osouli, A., Salam, S., Othmanawny, G., Tutumluer, E., Beshears, S., Shoup, H., \& Eck, M. (2017), Soaked And Unsoaked CBR Test Results On Unbound Aggregates With Varying Amounts Of Fines And Dust Ratio, USA.

Robert Nini (2018), Effect of Soil Loading Surcharge on its CBR Value, Balamand, El-Koura, Lebanon.

Sheikh S, Nusaeir H., Abdul J. and Mohammad S. (2016), Prediction of soaked cbr using index properties, dry density and unsoaked cbr of lean clay, Dhaka, Bangladesh. 